\title{
Stress patterns of two-implant mandibular overdentures depending on the types of attachments
}

\author{
Sung-Soo Yoon', Seoung-Jin Hong ${ }^{2}$, Janghyun Paek ${ }^{2}$, Kung-Rock Kwon ${ }^{2}$ \\ ${ }^{1}$ Private practice, Seoul, ${ }^{2}$ Department of Prosthodontics, School of Dentistry, Kyung Hee University, Seoul, Korea
}

Purpose: To analyze the stress pattern on two-implant mandibular overdentures using strain gauges.

Materials and Methods: Two implants and four types of attachments (magnet, locator, ball, and bar) were used with a mandibular implant-retained overdenture. The complete mandibular denture was fabricated on a model using the conventional method. Two implants connected with a strain gauge were installed on both sides of the canine areas. A vertical force of $50 \mathrm{~N}$ was applied on the left mandibular first molar area (case 1) and the left premolar and molar areas (case 2) of the denture. The resulting stress pattern was analyzed using the strain gauge and analyzer. The one-way analysis of variance method was used for statistical analysis at $\alpha=0.05$.

Results: In case 1, the lowest strain value was in the magnetic attachment, while the highest value was noticed in the bar attachment $(\mathrm{P}<0.05)$. There was no significant difference in strain values between the ball and locator attachments. In case 2 , significant differences in strain values were observed in all the types of attachments and the strain value increased in the order of the magnet, locator, ball, and bar attachment $(\mathrm{P}<0.05)$.

Conclusions: The strain values were different for each attachment, and the values increased in the order of the magnet, locator, ball, and bar attachment. (JOURNAL OF DENTAL IMPLANT RESEARCH 2021;40(3):112-119)

Key Words: Mandible, Implant-retained overdenture, Attachment system, Strain gauge, Working/balancing side

\section{INTRODUCTION}

Major complaint by fully edentulous patients regarding the complete denture has been its lack of retention, support, and stability. Chewing ability, furthermore life quality is compromised by these adverse conditions ${ }^{1,2}$. As the usage of implant became generalized, the implant overdenture has become an alternative to the complete denture for patients dissatisfied with the original treatment. According to The McGill Consensus Statement, two implant-retained overdentures should now be considered as the minimum standard of care for edentulous patients ${ }^{3}$. Also, several studies have reported the advantages of two-implant retained mandibular overdenture over the conventional complete denture in terms of retention, stability, pronunciation ${ }^{4,5)}$, masticatory efficiency ${ }^{6,7)}$, patient satisfaction $^{8}$, and decreasing the resorption of the anterior ridge ${ }^{7,9)}$.

Regarding the mandibular implant overdenture, many researches have been carried out on the biomechanical effect of the number, the type, and the prosthetic design of the implant attachment system and the overdenture $^{10-14)}$. According to Batenburg ${ }^{15)}$, there is no significant difference between the two-implant and the four-implant mandibular overdenture, suggesting that two implants are sufficient for retaining mandibular

Received August 2, 2021, Revised August 28, 2021, Accepted August 30, 2021. (c) Journal of Dental Implant Research.

This is an open access article distributed under the terms of the Creative Commons Attribution Non-Commercial License (http://creativecommons.org/licenses/by-nc/4.0) which permits unrestricted non-commercial use, distribution, and reproduction in any medium, provided the original work is properly cited.

Correspondence to: Kung-Rock Kwon, https://orcid.org/0000-0002-9777-8980

Department of Prosthodontics, School of Dentistry, Kyung Hee University, 26, Kyungheedae-ro, Dongdaemun-gu, Seoul 02447, Korea. Tel: +82-2-958-9340, Fax: +82-2-958-9423, E-mail: krkwon@khu.ac.kr 
overdenture. The two-implant overdenture also satisfies the demands of least invasive treatment, low cost, and prosthetic efficiency and simplicity proposed by Schmitt and Zarb for treating completely edentulous patients ${ }^{16)}$. In mandibular implant overdenture, various attachment systems have been used, and are generally divided into two systems, splinted and solitary attachment systems. Solitary system is advantageous for hygiene maintenance and less sensitive to the technique of the clinician ${ }^{11,13)}$. In contrast, splinted system achieves greater stability and retention $^{14)}$. However, the overload applied to the implant can cause bone resorption, and forces beyond the physiological range can cause microfracture of the bone, which will be healed with soft connective tissue, causing osseointegration to fail. Therefore, the type of attachment used for the retention system is an important factor that affects the magnitude of the force transferred to the supportive tissues, the implant, and the overdenture prosthe$\operatorname{sis}^{10,17,18)}$.

The aim of this study is to compare and analyze the levels and patterns of the stress applied to the implant through four different types of attachments: magnet, locator, ball, and bar. The comparisons will be clinically significant in determining which type of attachment will best suit the conditions of different patients.

\section{MATERIALS AND METHODS}

The experimental model was fabricated using the completely edentulous mandibular model (KHU CD-1; Nissin

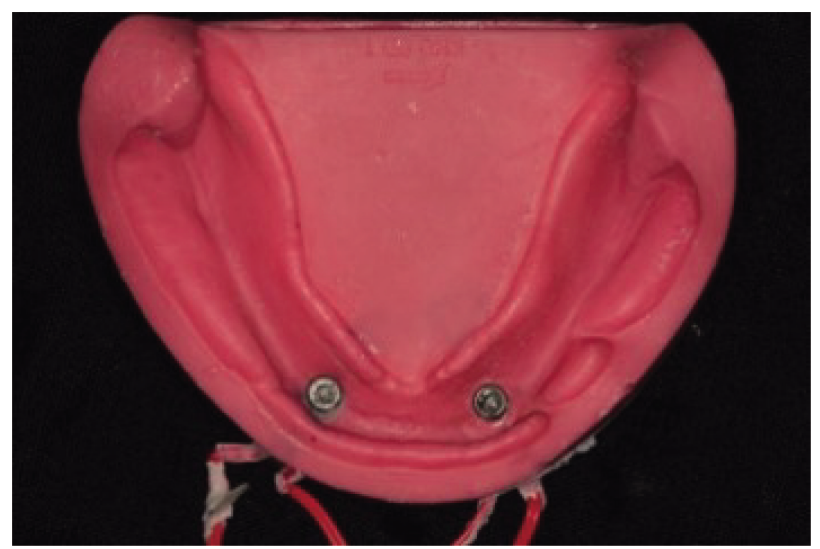

Fig. 1. Implants were placed on the \#33 and \#43 positions of completely edentulous mandibular model, and strain gauges were attached.
Dental Products Inc., Kyoto, Japan) with the epoxy resin (Polyurock; Metalor, Neuchâtel, Switzerland). A $2 \mathrm{~mm}$ thick edentulous soft tissue was reproduced using polyether impression material (Impregum Penta; 3M ESPE, CA, USA). The mandibular complete denture was manufactured by conventional method. Two tissue-level implants (diameter $4.1 \mathrm{~mm}$, length $10 \mathrm{~mm}$; Straumann, Basel, Switzerland) were placed perpendicular to the occlusal plane at the right and left canine area of the remaining mandibular alveolar ridge on the model. The strain gauge (length $4.8 \mathrm{~mm}$, width $2.4 \mathrm{~mm}$, KFG-1-120-C1-11 L1M2R; Kyowa Electronic Instruments, Tokyo, Japan) with a resistance of $120 \Omega$ that can measure in one direction on either the vertical or the lateral axis was chosen. For the tight contact of the strain gauge and the surface of the implant, buccal and mesial threads of the \#43 implant and lingual and distal threads of the \#33 implant were properly adjusted for flat surfaces. Two strain gauges were attached to each of the implants. For \#43 implant, one strain gauge was attached to its buccal side and another to its mesial side and for \#33 implant, one strain gauge was attached to its lingual side and another to its distal side (Fig. 1). The strain gauges attached to the same implant were thus at $90^{\circ}$ of each other. The buccal and lingual attachment sites were made close to the implant neck, and the
A

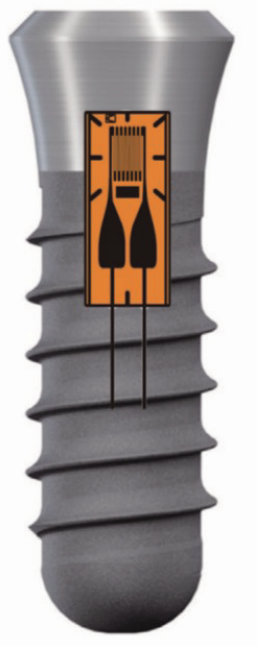

B

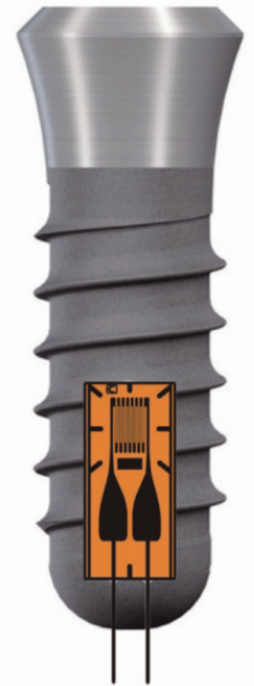

Fig. 2. Location of the strain gauge attached to the implant. (A) Lingual side of left canine implant and buccal side of right implant. (B) Distal side of left canine implant and mesial side of right implant. 
mesial and distal attachment sites were made close to the root apex (Fig. 2) ${ }^{14)}$. During the implantation, the strain gauges were covered in silicone for protection. In the duplicated epoxy model, $8 \mathrm{~mm}$ in diameter holes were prepared at both canine areas and implants were placed. To reproduce the osseointegration state, the implants were placed on the model using resin cement (Superbond CB; Sun Medical, Moriyama, Japan). Magnet attachment (Magfit IP-I; Aichi Steel Co., Tokai, Japan), locator attachment (blue color male component; Zest Anchors Inc., CA, USA), ball attachment (retentive anchor with titanium matrix; Straumann, Basel, Switzerland), and bar attachment (Dolder bar with spacer; Cendres \& Mètaux, Biel-Bienne, Switzerland), overall four types of attachments were connected to the implants. The abutment of each attachment system was tightened by $20 \mathrm{Ncm}$ torque according to the manufacturer's instructions, and in bar attachment system, suprastructure was tightened by $10 \mathrm{Ncm}$. The same denture was used throughout the experiment. When changing the attachments, relining was done using the autopolymerizing pink resin (Lang Dental Manufacturing

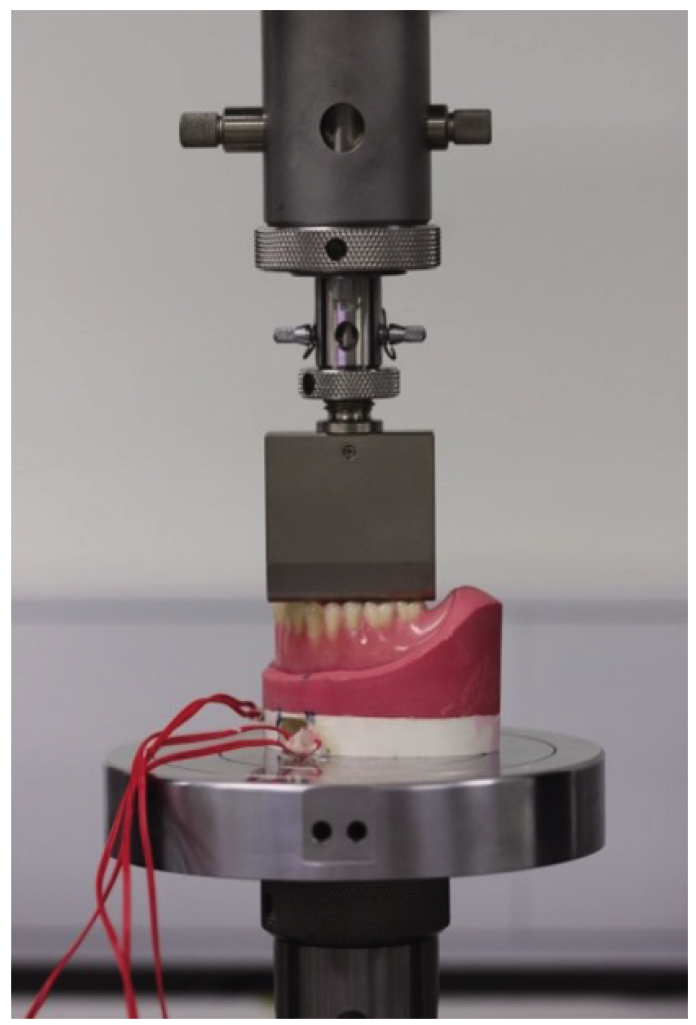

Fig. 3. Vertical loads were applied on each attachment type of implant-retained overdenture using by a universal testing machine.
Co., IL, USA).

A vertical load up to $50 \mathrm{~N}(0.5 \mathrm{~mm} / \mathrm{min})$ was applied on each attachment type of implant-retained overdenture. In case 1, vertical load was applied to the left mandibular first molar area, and in case 2, vertical load was applied to the left mandibular premolar and molar areas simultaneously (Fig. 3). A universal testing machine (Instron 3367; Instron Co., MA, USA) was used to apply the vertical load and this was repeated 10 times. Whenever the attachment was replaced, 1 day was given for recovery. The sensors of the strain gauges were connected to the strain data analyzer (PCD-300A; Kyowa Electronic Instruments, Tokyo, Japan) and the data exported to the personal computer (Sens X11; Samsung, Yongin, Korea).

For each cycle, the maximum absolute strain value was selected and the mean and standard deviation of $10 \mathrm{cy}-$ cles were statistically analyzed. Results were analyzed statistically with the SPSS software (ver. 17.0 for Windows; SPSS Inc., Chicago, IL, USA). All data were subjected to normality and homogeneity of variance on the Shapiro-Wilk test and the Levene test for each group. One-way ANOVA with post hoc Tukey's honestly significant difference test was performed. The significance level was set at $5 \%$.

\section{RESULTS}

In strain measurements, a positive strain value indicates a tensile force and a negative strain value indicates a compressive force. Comparing overall absolute strain values, in case 1 , the bar attachment showed the greatest absolute strain value, whereas the magnetic attachment showed the least absolute strain value, statistically $(\mathrm{P}<0.05)$. No significant difference was found between the mean strain values of the ball and the locator attachment $(\mathrm{P}>0.05)$. In case 2 , there were significant differences between all four attachment types $(P<0.05)$ with increasing order of magnet, locator, ball and bar attachment (Table 1).

In case 1 , on the working side (left canine site; 33iL, 33iD), the compressive force was predominant, whereas on the balancing side (right canine site; $43 \mathrm{iB}, 43 \mathrm{iM}$ ), the tensile force was predominant, except for the bar attachment, which showed the compressive force on the mesial 
Table 1. Overall mean absolute strain values and SD values of case 1 and case $2(\mu \mathrm{m} / \mathrm{m})$

\begin{tabular}{|c|c|c|c|c|c|c|c|c|c|}
\hline & \multicolumn{2}{|c|}{ Magnet } & \multicolumn{2}{|c|}{ Locator } & \multicolumn{2}{|c|}{ Ball } & \multicolumn{2}{|c|}{ Bar } & \multirow{2}{*}{$P$ value* } \\
\hline & Mean & SD & Mean & SD & Mean & SD & Mean & SD & \\
\hline Case 1 & $24.25^{\mathrm{a}}$ & $3.62^{a}$ & $90.88^{b}$ & $19.91^{b}$ & $124.50^{b}$ & $12.85^{b}$ & $173.76^{c}$ & $30.79^{c}$ & .02 \\
\hline Case 2 & $25.13^{a}$ & $5.79^{a}$ & $76.00^{b}$ & $19.73^{b}$ & $105.75^{c}$ & $14.85^{c}$ & $139.43^{d}$ & $14.66^{d}$ & .04 \\
\hline
\end{tabular}

Case 1: Applying vertical load to the left mandibular first molar area.

Case 2: Applying one-sided vertical load simultaneously to the left mandibular premolar and molar area.

SD: Standard deviation.

*The difference is significant at the level of 0.05 .

$\mathrm{a} \sim \mathrm{d}$ : The non-significant groups are expressed in same letter.

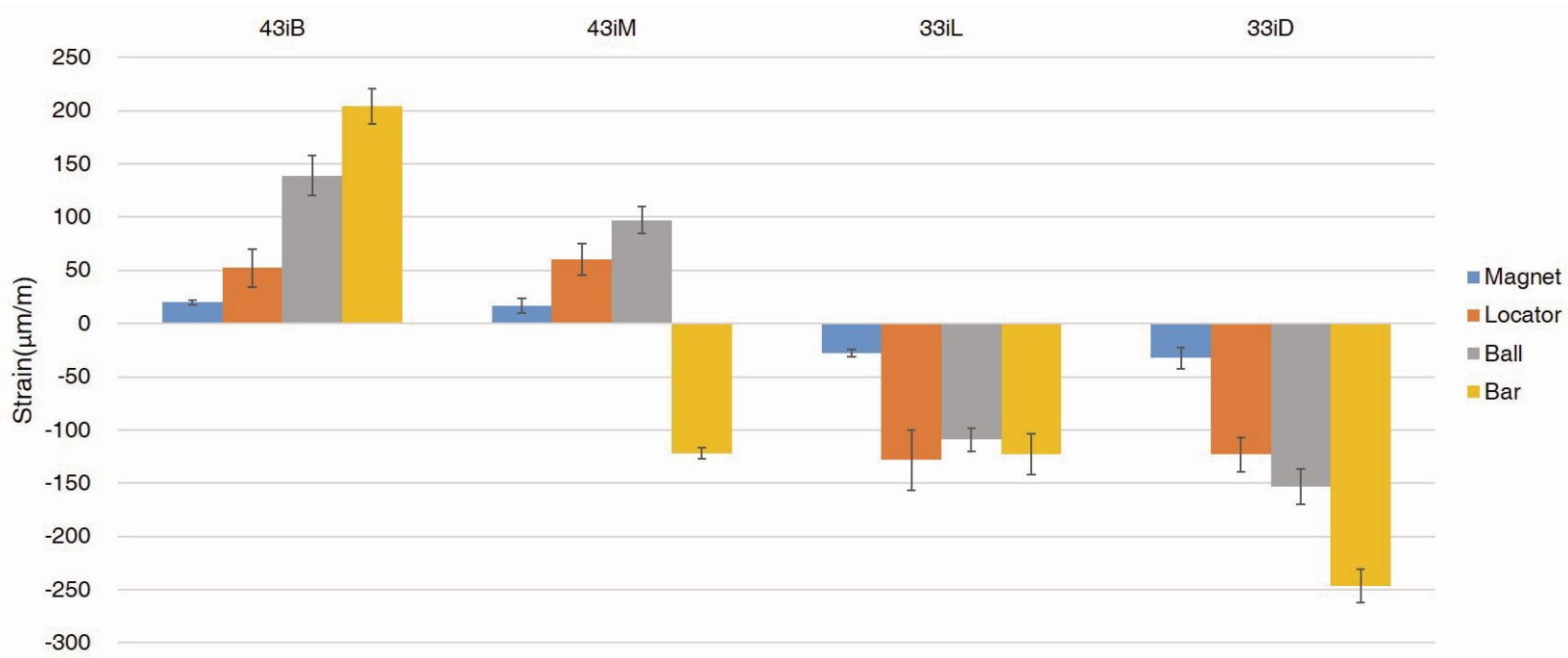

Fig. 4. Means and SDs of strain values $(\mu \mathrm{m} / \mathrm{m})$ when vertical load was applied to the left mandibular first molar. SD: Standard deviation. B: Buccal side, M: Mesial side, L: Lingual side, D: Distal side.

Table 2. Means and SDs of absolute strain values $(\mu \mathrm{m} / \mathrm{m})$ when vertical load was applied to the left mandibular first molar

\begin{tabular}{|c|c|c|c|c|c|c|c|c|}
\hline & \multicolumn{2}{|c|}{$43 \mathrm{iB}$} & \multicolumn{2}{|c|}{ 43іM } & \multicolumn{2}{|c|}{ 33iL } & \multicolumn{2}{|c|}{ 33iD } \\
\hline & Mean & SD & Mean & SD & Mean & SD & Mean & SD \\
\hline Magnet & $20.07^{a}$ & $2.32^{\mathrm{a}}$ & $16.50^{\mathrm{a}}$ & $6.87^{\mathrm{a}}$ & $28.03^{b}$ & $3.51^{b}$ & $32.50^{b}$ & $10.45^{b}$ \\
\hline Locator & $52.13^{c}$ & $18.1^{c}$ & $60.50^{c}$ & $14.74^{\mathrm{C}}$ & $128.09^{d}$ & $28.36^{d}$ & $123.03^{d}$ & $15.94^{d}$ \\
\hline Ball & $139.03^{\mathrm{e}}$ & $18.47^{\mathrm{e}}$ & $97.01^{f}$ & $12.72^{f}$ & $109.10^{\mathrm{g}}$ & $10.59^{g}$ & $153.07^{\mathrm{h}}$ & $16.33^{h}$ \\
\hline Bar & $204.22^{i}$ & $16.32^{i}$ & $121.92^{j}$ & $5.28^{j}$ & $122.30^{k}$ & $19.18^{k}$ & $246.80^{\prime}$ & $15.70^{\prime}$ \\
\hline
\end{tabular}

SD: Standard deviation.

B: Buccal side, M: Mesial side, L: Lingual side, D: Distal side.

*The difference is significant at the level of 0.05 .

$\mathrm{a} \sim$ I: The non-significant groups are expressed in same letter.

side of the implant (Fig. 4). For all four attachment types, the absolute strain values on the working side was greater in magnitude than the absolute strain values on the balancing side (Table 2). For the ball and the bar attachments, the absolute strain values on $43 \mathrm{iB}$ were significantly higher than those on $43 \mathrm{iM}$, and the absolute strain values on $33 \mathrm{iD}$ were significantly higher than those on 33iL $(\mathrm{P}<0.05)$. For the magnet and the locator attachments, there was no significant difference between the absolute strain values on $43 \mathrm{iB}$ and $43 \mathrm{iM}$, nor between the strain values on 33iL and 33iD ( $\mathrm{P}>0.05)$ (Table 2).

In case 2 , as in the previous case, the compressive force was predominant on the working side, whereas the tensile force was predominant on the balancing side, except 


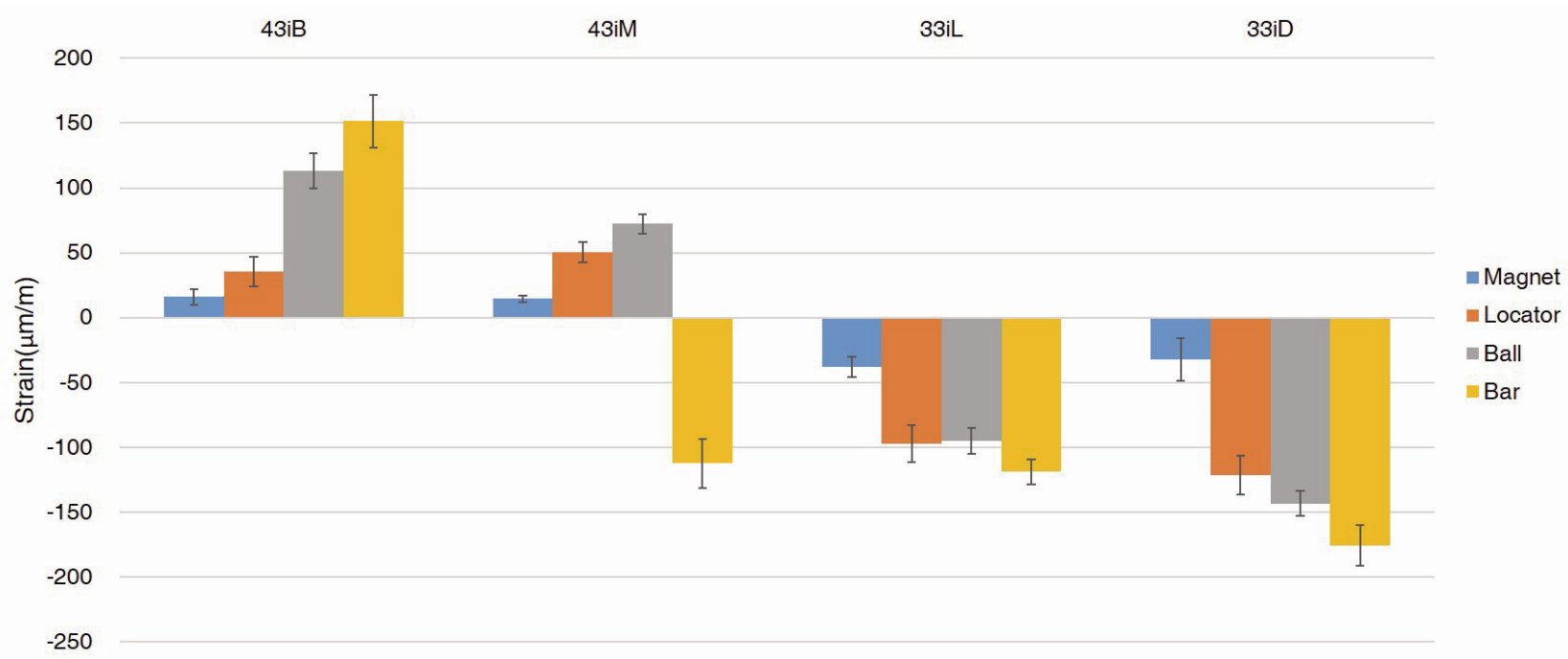

Fig. 5. Means and SDs of strain values $(\mu \mathrm{m} / \mathrm{m})$ when vertical load was applied to the left mandibular premolar and molar area. SD: Standard deviation. B: Buccal side, M: Mesial side, L: Lingual side, D: Distal side.

Table 3. Means and SDs of absolute strain values $(\mu \mathrm{m} / \mathrm{m})$ when vertical load was applied to the left mandibular premolar and molar area

\begin{tabular}{|c|c|c|c|c|c|c|c|c|}
\hline & \multicolumn{2}{|c|}{$43 \mathrm{iB}$} & \multicolumn{2}{|c|}{$43 i M$} & \multicolumn{2}{|c|}{ 33iL } & \multicolumn{2}{|c|}{$33 \mathrm{iD}$} \\
\hline & Mean & SD & Mean & SD & Mean & SD & Mean & SD \\
\hline Magnet & $16.01^{\mathrm{a}}$ & $6.11^{\mathrm{a}}$ & $14.50^{\mathrm{a}}$ & $2.65^{a}$ & $38.07^{\mathrm{b}}$ & $7.69^{b}$ & $32.02^{b}$ & $16.36^{b}$ \\
\hline Locator & $35.50^{c}$ & $11.18^{\mathrm{c}}$ & $50.50^{\circ}$ & $7.68^{\mathrm{c}}$ & $97.03^{d}$ & $14.51^{\mathrm{d}}$ & $121.41^{\mathrm{e}}$ & $15.22^{\mathrm{e}}$ \\
\hline Ball & $113.04^{f}$ & $13.65^{f}$ & $72.33^{g}$ & $7.24^{\mathrm{g}}$ & $95.01^{\mathrm{h}}$ & $9.86^{\mathrm{h}}$ & $143.11^{i}$ & $9.32^{i}$ \\
\hline Bar & $151.50^{j}$ & $20.25^{j}$ & $112.20^{k}$ & $18.98^{k}$ & $118.70^{\prime}$ & $9.68^{\prime}$ & $175.50^{\mathrm{m}}$ & $16.25^{\mathrm{m}}$ \\
\hline
\end{tabular}

SD: Standard deviation.

B: Buccal side, M: Mesial side, L: Lingual side, D: Distal side. *The difference is significant at the level of 0.05 .

$\mathrm{a} \sim \mathrm{m}$ : The non-significant groups are expressed in same letter.

for the bar attachment, which showed the compressive force on the mesial side of the implant (Fig. 5). For all four attachment types, the absolute strain values on the working side was greater in magnitude than the absolute strain values on the balancing side (Table 3). For the ball and the bar attachments, the absolute strain values on $43 \mathrm{iB}$ were significantly higher than those on 43iM. Also, the absolute strain values on $33 \mathrm{iD}$ were significantly higher than those on 33iL. For the locator attachment, there was no significant difference between $43 \mathrm{iB}$ and $43 \mathrm{iM}$, whereas the strain value on $33 \mathrm{iD}$ was significantly higher than that on 33iL. For the magnetic attachment, there was no significant difference between $43 \mathrm{iB}$ and 43iM, nor between 33iD and 33iL ( $\mathrm{P}>0.05)$ (Table 3).

\section{DISCUSSION}

It is controversial regarding the design and indications for different attachment systems for overdentures. The design of attachments should provide optimum stress distribution around supporting implants and tissues to allow bone loading within physiologic levels and the amount of stress transferred to the supportive tissues of the implant is an important factor to consider when treating fully edentulous patients as it can cause bone resorption and microfracture.

This study measured and compared the level of stress transferred to the implant through the four different types of attachments used for the retention system: magnet, locator, ball, and bar. The measurements were taken by applying vertical load to the two implant-retained 
mandibular overdenture and using strain gauge to measure the stress transferred to the implant. The strain gauge is closely adhered to the object to be measured and the length changes with the object, and the length of the sensing element also changes. The resistance value of all metals changes when a change in length occurs. The strain gauge can be used to measure strain by measuring the change in resistance value and to calculate the principal stress using this principle. Although the strain gauge analysis has several limitations of the in vitro study, it can measure actual strain compared to finite element analysis. The vertical load was applied to the left mandibular first molar area, whereas in the other case, the load was applied to the left mandibular premolar and molar area simultaneously, considering the prosthetic characteristics of the denture. In both cases, the compressive strain was predominant on the working side, whereas the tensile strain was predominant on the balancing side. Also in both cases, the compressive strain on the working side was greater in magnitude than the tensile strain on the balancing side, and this applied to all four attachments. This result consistent with the findings of Khurana et al. ${ }^{10)}$. The intermittent stress is more physiologic to bone than continuous stress, likewise, the compressive stress is more physiologic to bone than tensile and shear stresses ${ }^{19)}$. The implant-retained overdenture is a compatible prosthesis with bone physiology, and in this study, it was confirmed that the compressive strain is larger than the tensile strain.

The strain values of each type of attachments were measured and compared. The magnetic attachment showed the least strain among the four types of attachment. According to the previous studies Gonda et al. $^{20)}$, the magnetic attachment can function as a stress breaker by acting as a buffer to the lateral and vertical movement of the prosthesis. Ichikawa et al. $^{21)}$ reported that the magnetic attachment can avoid lateral force because the magnet can slide at the keeper part and avoid occlusal force because it has low vertical retention. Based on these previous studies, the flat type magnetic attachment in the present study showed the lowest stress on the implant itself most likely by partially sliding at the keeper. The ball attachment showed greater stress on the implant than the locator attachment. The male part of the ball attachment is higher in height than that of the locator attachment. Maeda et al. ${ }^{22)}$ reported that, while this additional height of the ball attachment allows more stability, it increases the lateral force that the implant receives. Therefore, the higher height of the ball attachment most likely caused greater stress on the implant than the locator attachment. Also, in the current study, the male part of the locator attachment was made of nylon, while that of the ball attachment was made of titanium, the nylon can act as a better buffer to stress than metal, the nylon component of the locator attachment may have contributed to its having lower stress on the implant than the ball attachment. The bar attachment, overall, showed the greatest strain among the four types of attachment, which is in accordance with previous studies ${ }^{23-25)}$. Although there is space for stress breaking at the bar attachment, by rigidly connecting the two implants with a metal bar, the bar attachment strongly restricts the movement of the implant compared to the solitary types (ball and locator attachments), thereby showing the greatest stress on the implant when force is applied. A preload of the bar attachment is also affected the strain value, because the bar attachment is connecting two implants, the strain is remained in the implants in the connecting procedure of the attachment. However, this strain occurs also in clinical situation, therefore, the overall strain value should be considered. The favorable range of the strain value to alveolar bone remodeling is generally accepted from 50 to 1,500 microstrain, and over 1,500 microstrain is considered overloading, which could cause microdamage to the alveolar bone ${ }^{26,27)}$. Contrarily, based on these criteria, the strain value in the magnet attachment was too low, an atrophy of alveolar bone should be considered.

The strain values of the buccal and the mesial side of the implant on the balancing side (43iB and $43 \mathrm{iM})$ and those of the lingual and the distal side of the implant on the working side (33iL and 33iD) were compared for each of the four attachments. For the ball and the bar attachments, the strain values on $43 \mathrm{iB}$ were significantly higher than those on $43 \mathrm{iM}$ in both cases 1 and 2 . If the overdenture/implant system is thought of as a lever, $43 \mathrm{iB}$ is further away from the pivot (which would be the implant on the working side) than $43 \mathrm{iM}$, and therefore, when 
pressure is applied on the other side of the pivot, $43 \mathrm{iB}$ will receive more tensile force. Also, the strain values on 33iL were significantly lower than those on 33iD in both cases 1 and 2. 33iD is closer to the point of the load than 33iL, and therefore will receive more compressive force than 33iL. For the locator attachment, there were no significant differences between $43 \mathrm{iB}$ and $43 \mathrm{iM}$, nor between $33 \mathrm{iL}$ and $33 \mathrm{iD}$, except in case 2, where it showed lower strain values on $33 \mathrm{iL}$ than on $33 \mathrm{iD}$. It is presumed that when the load is applied to the left mandibular premolar and molar areas simultaneously, the lateral force is less than the load is applied only the left mandibular first molar, the strain value is decreased at the \# 33iL on the working side. For the magnetic attachment, no significant differences were found between $43 \mathrm{iB}$ and $43 \mathrm{iM}$, nor between 33iL and 33iD in both cases 1 and 2. This is most likely because the male and the female parts of the locator attachment and the magnetic attachment partially detaches and the height of the attachment acting as a lever is low, thereby alleviating the stress on the implant. In both cases, the bar attachment showed compressive strain values for $43 \mathrm{iM}$, for which all other attachments showed tensile strain values. The bar attachment rigidly connects the two implants by a metal bar. It may be that, when the load is applied, the force is transferred to the bar itself, thereby allowing the bar attachment, which is in between the two implants, to also be the source of the downward force. When this happens, the mesial side of the balancing side implant faces the bar, the secondary source of the downward force, and thereby experiences compressive force rather than tensile force. The buccal side of the same implant faces away from the bar, and will thereby experience tensile force. Therefore, especially in the bar attachment, bone resorption and microfracture should be noted by tensile force, because the buccal bone wall is relatively thin, however, considering the absolute stain value, this complication has low incidence. In the magnet attachment, bone atrophy should be considered.

The limitation of this study is in vitro study, and there are some differences from the condition of the oral cavity. The size of the strain gauges used in this experiment was relatively large compared to the size of the implant, and it was difficult to place to the implant, precisely. In addition, the measurement position of the strain value was limited. However, in this study, the strain values was evaluated in four attachment systems in the two implant-retained mandibular overdenture, these strain values should be considered when using attachment systems in clinical situation.

\section{CONCLUSION}

All four attachment system in the two implant-retained mandibular overdenture, the implants mandibular overdenture the implants on the working side showed compressive strain values, whereas the implants on the balancing side showed tensile strain values, except for the bar attachment, which showed compressive strain values on the mesial side of the balancing side implant. Overall, the stress levels on the working side implants were greater in magnitude than the stress levels on the balancing side implants. The bar attachment showed the highest strain value, the ball attachment showed the second strain value, the locator attachment showed the third strain value, and the magnetic attachment showed the lowest strain value. Considering only the stress on the implant and supportive tissues, when using the bar attachment, it is recommended to consider the resorption of the buccal bone, and the magnet attachment could be considered in patients with weak supportive tissues and risk of bone resorption.

\section{ORCID}

Seoung-Jin Hong, https://orcid.org/0000-0002-7460-8487 Janghyun Paek, https://orcid.org/0000-0002-1286-3140 Kung-Rock Kwon, https://orcid.org/0000-0002-9777-8980

\section{REFERENCES}

1. Van Waas MAJ. The influence of clinical variables on patients' satisfaction with complete dentures. J Prosthet Dent 1990;63:307-10.

2. Burns DR. The mandibular complete overdenture. Dent Clin North Am 2004;48:603-23, v-vi.

3. Thomason JM, Kelly SA, Bendkowski A, Ellis JS. Two implant retained overdentures - a review of the literature supporting the McGill and York consensus statements. J Dent 2012;40: 22-34.

4. Meijer HJA, Raghoebar GM, Van 't Hof MA. Comparison of im- 
plant-retained mandibular overdentures and conventional complete dentures: a 10-year prospective study of clinical aspects and patient satisfaction. Int J Oral Maxillofac Implants 2003;18:879-85.

5. ELsyad MA, Errabti HM, Mustafa AZ. Mandibular Denture Base Deformation with locator and ball attachments of implant-retained overdentures. J Prosthodont 2016;25:656-64.

6. Boerrigter EM, Stegenga B, Raghoebar GM, Boering G. Patient satisfaction and chewing ability with implant-retained mandibular overdentures: a comparison with new complete dentures with or without preprosthetic surgery. J Oral Maxillofac Surg 1995;53:1167-73.

7. Farias Neto A, Pereira BM, Xitara RL, Germano AR, Ribeiro JA, Mestriner Junior $\mathrm{W}$, et al. The influence of mandibular implant-retained overdentures in masticatory efficiency. Gerodontology 2012;29:e650-5.

8. Assuncao WG, Barao VA, Delben JA, Gomes EA, Tabata LF. A comparison of patient satisfaction between treatment with conventional complete dentures and overdentures in the elderly: a literature review. Gerodontology 2010;27:154-62.

9. Atwood DA, Coy WA. Clinical, cephalometric, and densitometric study of reduction of residual ridges. J Prosthet Dent 1971;26:280-95.

10. Khurana N, Rodrigues S, Shenoy S, Saldanha S, Pai U, Shetty $\mathrm{T}$, et al. A comparative evaluation of stress distribution with two attachment systems of varying heights in a mandibular implant-supported overdenture: a three-dimensional finite element analysis. J Prosthodont 2019;28:e795-805.

11. Seo YH, Bae EB, Kim JW, Lee SH, Yun MJ, Jeong CM, et al. Clinical evaluation of mandibular implant overdentures via locator implant attachment and locator bar attachment. J Adv Prosthodont 2016;8:313-20.

12. Lee $E$, Shin SY. The influence of the number and the type of magnetic attachment on the retention of mandibular mini implant overdenture. J Adv Prosthodont 2017;9:14-21.

13. Awad MA, Rashid F, Feine JS, Overdenture Effectiveness Study Team Consortium. The effect of mandibular 2-implant overdentures on oral health-related quality of life: an international multicentre study. Clin Oral Implants Res 2014;25:46-51.

14. Yoo JS, Kwon KR, Noh K, Lee H, Paek J. Stress analysis of man- dibular implant overdenture with locator and bar/clip attachment: comparative study with differences in the denture base length. J Adv Prosthodont 2017;9:143-51.

15. Batenburg RH, Raghoebar GM, Van Oort RP, Heijdenrijk K, Boering $G$. Mandibular overdentures supported by two or four endosteal implants. A prospective, comparative study. Int J Oral Maxillofac Surg 1998;27:435-9.

16. Schmitt A, Zarb GA. The notion of implant-supported overdentures. J Prosthet Dent 1998;79:60-5.

17. Zarb GA, Schmitt A. Implant prosthodontic treatment options for the edentulous patient. J Oral Rehabil 1995;22:661-71.

18. Isidor F. Loss of osseointegration caused by occlusal load of oral implants. A clinical and radiographic study in monkeys. Clin Oral Implants Res 1996;7:143-52.

19. Devan MM. Basic principles in impression making. 1952. J Prosthet Dent 2005;93:503-8.

20. Gonda T, Ikebe K, Ono T, Nokubi T. Effect of magnetic attachment with stress breaker on lateral stress to abutment tooth under overdenture. J Oral Rehabil 2004;31:1001-6.

21. Ichikawa T, Horiuchi M, Wigianto R, Matsumoto N. In vitro study of mandibular implant-retained overdentures: the influence of stud attachments on load transfer to the implant and soft tissue. Int J Prosthodont 1996;9:394-9.

22. Maeda Y, Horisaka M, Yagi K. Biomechanical rationale for a single implant-retained mandibular overdenture: an in vitro study. Clin Oral Implants Res 2008;19:271-5.

23. Kenney R, Richards MW. Photoelastic stress patterns produced by implant-retained overdentures. J Prosthet Dent 1998;80:559-64.

24. Tokuhisa M, Matsushita Y, Koyano K. In vitro study of a mandibular implant overdenture retained with ball, magnet, or bar attachments: comparison of load transfer and denture stability. Int J Prosthodont 2003;16:128-34.

25. Porter JA, Jr., Petropoulos VC, Brunski JB. Comparison of load distribution for implant overdenture attachments. Int J Oral Maxillofac Implants 2002;17:651-62.

26. Frost HM. A 2003 update of bone physiology and Wolff's Law for clinicians. Angle Orthod 2004;74:3-15.

27. Glantz PO, Nilner K. Biomechanical aspects of prosthetic implant-borne reconstructions. Periodontol 1998;17:119-24. 